\title{
Investigation of wound healing in rat lung tissues in the postpartum period
}

\author{
SULE KARADAYI ${ }^{1}$, EKBER SAHIN $^{2}$, AYDIN NADIR $^{2}$, ERSIN TUNCER $^{3}$, YAVUZ SILIG $^{4}$, \\ ILHAN KORKMAZ $^{1}$, FATOS TANZER ${ }^{5}$, HAFIZE SEZER ${ }^{6}$ and MELIH KAPTANOGLU ${ }^{2}$
}

\author{
Departments of ${ }^{1}$ Emergency Medicine, ${ }^{2}$ Thoracic Surgery, ${ }^{3}$ Pathology, ${ }^{4}$ Biochemistry, ${ }^{5}$ Pediatrics, and ${ }^{6}$ Biostatistics, \\ Cumhuriyet University School of Medicine, Sivas 58140, Turkey
}

Received December 14, 2011; Accepted January 30, 2012

DOI: $10.3892 /$ etm.2012.495

\begin{abstract}
To assess the wound healing capabilities of damaged lung tissue in the postpartum period, we investigated the parameters related to wound healing in a rat model of lung damage. Rats were divided into six groups: IA, IB, II, IIIA, IIIB and IV ( $\mathrm{n}=7$ in each group). Group IA included rats not in the postpartum period that were sacrificed on the third day after lung injury, group IB included rats not in the postpartum period that were sacrificed on the tenth day after lung injury, group II included rats not in the postpartum period that did not receive lung injury, group IIIA included rats in the postpartum period that were sacrificed on the third day after lung injury, group IIIB included rats in the postpartum period that were sacrificed on the tenth day after lung injury and group IV included rats in the postpartum period without lung injury. Wound healing was evaluated histopathologically and measurements of hydroxyproline levels, serum alanine and glutamine were taken. A significant difference in serum alanine levels was evident between groups IA and IIIA. Significant differences were also observed between serum alanine and glutamine levels in groups IB and IIIB. In conclusion, we demonstrated that serum alanine levels were reduced in the postpartum period following lung injury, which may be expected to negatively impact wound healing in this period. The administration of exogenous alanine for traumatic events occurring during the postpartum period may thus contribute positively to wound healing capabilities during this period.
\end{abstract}

\section{Introduction}

Wound healing is a sequence of events involving cellular and biochemical mechanisms that results in new granulation

Correspondence to: Dr Sule Karadayi, Department of Emergency Medicine, Cumhuriyet University School Of Medicine, Sivas 58140, Turkey

E-mail: sulekaradayi73@yahoo.com

Key words: pneumothorax, rat, wound healing, lung, postpartum period tissue (1). Wound healing occurs in all tissues through the same mechanisms, divided into three phases: i) hemostasis and inflammation (from 1 to 4 days) that occur immediately following injury and result in the aggregation and activation of thrombocytes, migration of leukocytes into the wound, vascular dilatation, and lymphatics surrounding the area; ii) proliferation then occurs (days 4-21), whereby fibroblasts enter the wound and the synthesis of collagen is initiated; and iii) maturation and remodeling (day 21 to 1 year) occurs, resulting in the production of type 1 collagen, which is then replaced by the stronger type 3 collagen. A discontinuation of any of the three phases delays wound healing $(2,3)$. Alanine and glutamine are amino acids that provide energy sources for rapidly proliferating cells. Glutamine is an important precursor for nucleic acid biosynthesis in all cells. Their use in the body increases in situations of disease, trauma, or stress, and thus exogenous dietary replacement may be helpful during these periods. Alanine and glutamine are also considered to be important in wound healing $(4,5)$.

Few studies have investigated the potential problems in wound healing in the postpartum period due to hormonal imbalances (6). We previously observed clinically that women in the postpartum period who develop pneumothorax show delayed healing and delayed cessation of the air leak occurring when a tube is introduced. We therefore suggest that wound healing in the lung tissue may be decreased during the postpartum period. In this study, we examined parameters related to wound healing in injured lung tissue from rats in the postpartum period.

\section{Materials and methods}

Animals and procedure. Prior to the main study, we performed preliminary surgical experiments to identify the lung injury to be introduced. A 15 -gauge needle beneath the second nipple, $1.4 \mathrm{~cm}$ inwards, was the confirmed method and the injury was visible macroscopically when the lungs were removed. The study rats were female Wistar albino rats weighting $220 \pm 20 \mathrm{~g}$ $(\mathrm{n}=42)$. These rats were divided into six groups. Group IA included rats not in the postpartum period that were sacrificed on the third day after lung injury, group IB included rats not in the postpartum period that were sacrificed on the tenth day after lung injury, group II included rats not in the postpartum 
period that did not receive lung injury, group IIIA included rats in the postpartum period that were sacrificed on the third day after lung injury, group IIIB included rats in the postpartum period that were sacrificed on the tenth day after lung injury and group IV included rats in the postpartum period without lung injury. Each group comprised seven rats. Prior to the injury procedure, the rats were anesthetized with $90 \mathrm{mg} / \mathrm{kg}$ of subcutaneous ketamine- $\mathrm{HCl}$ and sacrificed following injury with $200 \mathrm{mg} / \mathrm{kg}$ of pentothal sodium, administered intraperitoneally. This study was approved by the Cumhuriyet University Local Ethics Committee for Experiments on Animals (B.30.2. CUM.0.01.00.00-50/307).

Measurement of lung tissue hydroxyproline OH-P. Lung tissue was rinsed with distilled water, dried with absorbent paper, weighed and sliced into small sections. The specimens were then dried in open-mouthed beakers at $100^{\circ} \mathrm{C}$ for $72 \mathrm{~h}$. Dried specimens were hydrolyzed in $6 \mathrm{M} \mathrm{HCl}$ at $110^{\circ} \mathrm{C}$ for $18 \mathrm{~h}$. The specimens were then washed three times with distilled water and dissolved in $2 \mathrm{ml}$ of buffer containing acetic acid 1.2\%, sodium acetate $12 \%$, citric acid $5 \%$ and sodium hydroxide $3.4 \%$, pH 6. Chloramine- $\mathrm{T}(0.5 \mathrm{ml}$ per $1 \mathrm{ml}$ of specimen $)$ was added to the specimens, which were then incubated at room temperature for $20 \mathrm{~min}$. A mixture of perchloric acid $15.6 \%$ and dimethylaminobenzaldehyde, dissolved in $0.5 \mathrm{ml}$ of propanol, was then added. Following incubation at $60^{\circ} \mathrm{C}$ for $15 \mathrm{~min}$, the absorbance was read using a spectrophotometer at $550 \mathrm{~nm}$. A standard curve was plotted for the OH-P content $(\mathrm{mg} / \mathrm{g})$ of the specimens $(7,8)$.

Serum alanine and glutamine measurements. Plasma samples (7 $\mu \mathrm{l})$ were spotted at $3-\mathrm{cm}$ intervals on 3MM Whatman chromatography paper. The amino acids were then separated over $16 \mathrm{~h}$ in acetic acid-butanol-distilled water. The chromatograms were removed from the solution, dried and stained with ninhydrin-acetone dye. The amino acids moved depending on their molecular weights and their positions were interpreted by comparison with standards. Samples with elevated levels of amino acids were analyzed with gas chromatography.

Histopathological evaluation of wound healing. Lung specimens were fixed in $10 \%$ formaldehyde for a minimum of $24 \mathrm{~h}$ and embedded in paraffin blocks. Slide sections (5 $\mu \mathrm{m}$-thick) were taken from the paraffin blocks and stained with hematoxylin and eosin (H\&E) and Masson's trichrome (MT) stains. H\&E- and MT-stained slides were examined in a blinded manner according to the intensity of inflammation, the intensity of fibroblastic proliferation, neovascularisation and the levels of edema and collagen using a modified 0-4 Ehrlich and Hunt numerical scale. These parameters were independently evaluated using a histopathological grading scale (Table I).

Statistical analyses. Data are presented as the means \pm SD. A Mann-Whitney U-test was performed for comparisons between groups.

\section{Results}

Histopathological findings. Upon histopathological examination, the lung tissues showed minor differences among the
Table I. Histopathological grading scale.

\begin{tabular}{ll}
\hline Grade & Presence of collagen \\
\hline 0 & No evidence \\
1 & Occasional evidence \\
2 & Light scattering \\
3 & Abundant evidence \\
4 & Confluent cells or fibers \\
\hline
\end{tabular}

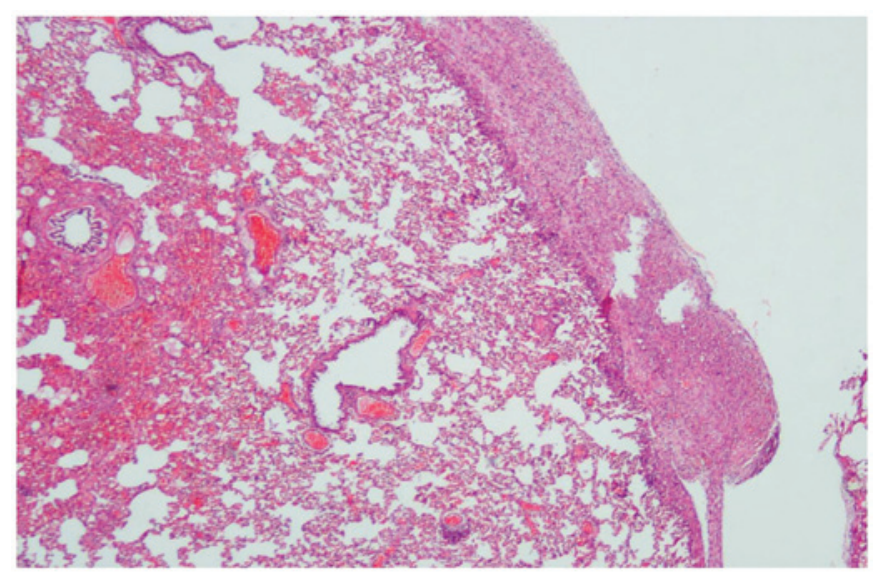

Figure 1. Fibrosis and pleural thickening with mild inflammatory processes in the IIIB group. (H\&E; magnification, $\mathrm{x} 40$ ).

groups. In the control groups with no trauma or perforation, no inflammation or fibrosis was evident. In the trauma groups, which were either pre- or postpartum, histopathological changes were characterised by minimal acute inflammation, hemorrhage, and almost no fibrosis in either the pleura or lung parenchyma. In the two groups sacrificed 10 days after trauma, chronic inflammation and fibrosis occurred, although this was the case in relatively few specimens (Fig. 1). Regarding fibrosis, MT staining was not different between the groups. With regard to wound healing, the levels of $\mathrm{OH}-\mathrm{P}$ in the lungs, and the mean serum values of alanine and glutamine are presented in Table II.

When the groups and variables were compared using the Mann-Whitney U-test, a significant difference in serum alanine levels was observed between groups IA and IIIA. The differences between the IB and IIIB groups were significant only for the serum alanine and glutamine levels.

\section{Discussion}

The wound healing process involves a series of events, including the production of collagen fibers, re-epithelialization, and neovascularization of newly developed connective tissue (1). The most common cause of spontaneous pneumothorax is the rupture of the apical subpleural blebs (9). In pneumothorax, the cascade of wound healing should occur to prevent air leakage. When a thorax tube is inserted accurately and pulmonary expansion is properly ensured, the pleuron repairs itself within $24-48 \mathrm{~h}$ and the air leak is stopped. However, a 
Table II. Mean values of wound healing parameters in the study groups.

\begin{tabular}{lccccccr}
\hline & \multicolumn{7}{c}{ Study group } \\
\cline { 2 - 6 } Parameters & IA & IB & II & IIIA & IIIB & IV & P-value \\
\hline Inflammation score (mean) & $1.29 \pm 0.8$ & $0.71 \pm 0.5$ & $0.29 \pm 0.5$ & $1.00 \pm 0.0$ & $1.00 \pm 0.6$ & $0.14 \pm 0.4$ & $\mathrm{p}>0.05$ \\
Blood vessel proliferation & $0.29 \pm 0.5$ & $1.14 \pm 0.7$ & $0.00 \pm 0.0$ & $0.57 \pm 0.5$ & $1.29 \pm 0.5$ & $0.14 \pm 0.4$ & $\mathrm{p}>0.05$ \\
Intensity of fibroblasts & $0.43 \pm 0.8$ & $1.14 \pm 0.7$ & $0.00 \pm 0.0$ & $0.57 \pm 0.5$ & $1.71 \pm 1.0$ & $0.00 \pm 0.0$ & $\mathrm{p}>0.05$ \\
Collagen & $0.43 \pm 0.8$ & $1.00 \pm 0.8$ & $0.00 \pm 0.0$ & $0.86 \pm 0.9$ & $1.00 \pm 0.8$ & $0.00 \pm 0.0$ & $\mathrm{p}>0.05$ \\
Lung OH-P (mg/g) & $7.60 \pm 0.3$ & $7.94 \pm 0.6$ & $7.91 \pm 0.3$ & $7.78 \pm 0.6$ & $7.10 \pm 1.2$ & $7.85 \pm 0.3$ & $\mathrm{p}>0.05$ \\
Serum alanine (mg/dl) & $5.11 \pm 0.6$ & $5.27 \pm 0.6$ & $3.46 \pm 0.7$ & $4.11 \pm 0.9$ & $3.88 \pm 1.1$ & $4.50 \pm 0.8$ & $\mathbf{p}<\mathbf{0 . 0 5}$ \\
Serum glutamine (mg/dl) & $0.60 \pm 1.0$ & $0.59 \pm 1.6$ & $0.00 \pm 0.0$ & $1.46 \pm 0.4$ & $1.51 \pm 0.5$ & $1.22 \pm 0.6$ & $\mathrm{p}>0.05$ \\
\hline
\end{tabular}

$\mathrm{OH}-\mathrm{P}$, hydroxyproline. Bold text indicates statistical significance.

systemic cause that affects wound healing may delay recovery from pneumothorax.

In previous studies an experimental pneumothorax was produced by damaging the parietal pleura alone (10-12). As we considered wound healing occurring in the visceral pleura and lung tissue, we created a minimal injury that damaged the lungs, but did not lead to mortality.

Increased collagen production from fibroblasts is important to the healing process. The newly produced fibers of collagen account for the strength of the surrounding connective tissue. Thus, wound healing involves a balance between the synthesis and degradation of collagen. It is well known that in newly formed connective tissue, the fibroblastic bridges do not occur prior to the first 3-5 days after incision and that collagen deposition occurs towards the end of the first week. Thereafter, neovascularization of newly formed granulation tissue occurs $(1,13-15)$. In this study, we independently evaluated rats on the third and tenth days to allow individual assessment of the early phase of wound healing, in which inflammatory cell infiltration occurs, and the later phase of healing, in which collagen deposition occurs. In this study, we observed no significant difference between the postpartum period examined on days 3 and 10 in terms of wound healing, inflammation score, the proliferation of blood vessels, fibroblast density or collagen deposition.

$\mathrm{OH}-\mathrm{P}$, the most common amino acid found in the collagen structure, is an important marker of collagen concentration. In many studies, OH-P levels were measured to assess wound healing and fibrosis $(1,16,17)$. In the study by O'Sullivan et al (18), higher OH-P levels were observed in subjects showing improved wound healing. In studies of intestinal anastomoses, Yamaguchi et al (16) reported elevated levels of OH-P in subjects with better wound healing. In this study, although the levels of OH-P were increased in rats not in the postpartum period, no statistically significant difference between the rats in the postpartum period was observed. This may indicate that $\mathrm{OH}-\mathrm{P}$ levels are somewhat lower in the postpartum period, leading to impaired wound healing.

In states of trauma or stress, the body's use of alanine and glutamine increases (4). In this study, serum alanine levels were lower in rats in the postpartum period compared with those not in the postpartum period. This may indicate that alanine usage increased during the postpartum period, meaning that insufficient alanine was available for body wound repair, contributing to impaired wound healing.

Placental growth factor (PIGF) is an important angiogenic factor primarily secreted by the placenta, but also present in the heart, lungs, thyroid, skeletal muscles and fatty tissue (19). Despite the presumed high PIGF levels during pregnancy and in the postpartum period, which may be expected to lead to improved wound healing in lung tissue, no differences were observed between the groups in terms of wound healing in the present study.

In conclusion, we demonstrated that serum alanine levels were decreased in postpartum rats, which may lead to negative effects on wound repair. Additionally, our findings suggest that exogenous alanine may contribute positively to wound healing capacity in response to trauma in the postpartum period.

\section{Acknowledgements}

This work was supported by the Scientific Research Project Fund of Cumhuriyet University, under project number T-406.

\section{References}

1. Turan M, Saraydin SU, Bulut HE, et al: Do vascular endothelial growth factor and basic fibroblast growth factor promote phenytoin's wound healing effects in rat? An immunohistochemical and histopathologic study. Dermatol Surg 30: 1303-1309, 2004.

2. Barbul A: Wound healing. In: Schwartz's Principles Of Surgery. Brunicardi FC, Andersen DK, Billiar TR, Dunn DL, Hunter JG and Pollock RE (eds). 8th edition. McGraw-Hill, New York, NY, pp223-248, 2005.

3. Erbil Y: Yara Iyilesmesi. In: Genel Cerrahi Cilt-1. Istanbul Tip Fakültesi Temel ve Klinik Bilimler Ders Kitapları. Göksel Kalayci (ed). Nobel Tip Kitabevi, Istanbul, pp51-60, 2002.

4. Soeters PB, van de Poll MC, van Gemert WG and Dejong CH: Amino acid adequacy in pathophysiological states. J Nutr 134: 1575-1582, 2004.

5. Peng $X$ and Wang SL: Glutamine and immunonutrition for burn patients. Zhonghua Shao Shang Za Zhi 25: 321-324, 2009.

6. Andreassen TT, Fogdestam I and Rundgren A: A biomechanical study of healing of skin incisions in rats during pregnancy. Surg Gynecol Obstet 145: 175-178, 1977.

7. Edwards CA and O'Brien WD Jr: Modified assay for determination of hydroxyproline in a tissue hydrolyzate. Clinica Chimica Acta 104: 161-167, 1980. 
8. Bergman I and Loxley R: Two improved and simplified methods for the spectrophotometric determination of hydroxyproline. Anal Chem 35: 1961-1965, 1963.

9. De Hoyos A and Fry WA: Pneumothorax. In: General Thoracic Surgery. Shields MD, Thomas W, LoCicero J, Reed CE and Feins RH (eds). 7th edition. Lippincott Williams \& Wilkins, Philadelphia, PA, pp739-761, 2009.

10. Akkas Y, Sahin E, Celik B, et al: An experimental model to study pneumothorax in rats. Sci Res Essays 5: 77-80, 2010.

11. Hill RC, Decarlo DP, Hill JF, Beamer KC, Hill ML and Timberlake GA: Resolution of experimental pneumothorax in rabbits by oxygen therapy. Ann Thorac Surg 59: 825-828, 1995.

12. England GJ, Hill RC, Timberlake GA, et al: Resolution of experimental pneumothorax in rabbits by graded oxygen therapy. J Trauma 2: 333-334, 1998

13. Forrest L: Current concepts in soft connective tissue wound healing. Br J Surg 70: 133-140, 1983.

14. Hardy MA: The biology of scar formation. Phys Ther 69: 1014-1024, 1989
15. Robbins S, Cotron R and Vinay K: Healing and repair. In: Pathologic Basis of Disease. Robbins S and Cotron R (eds). 3rd edition. Saunders, Philadelphia, PA, pp69-81, 1984.

16. Yamaguchi $\mathrm{R}$, Terashima $\mathrm{H}$, Yoneyama $\mathrm{S}$, Tadano $\mathrm{S}$ and Onkohchi N: Effects of platelet-rich plasma on intestinal anastomotic healing in rats: PRP concentration is a key factor. J Surg Res: doi:10.1016/J.Jss.2010.10.001.

17. Ohbayashi M, Suzuki M, Yashiro Y, et al: Induction of pulmonary fibrosis by methotrexate treatment in mice lung in vivo and in vitro. J Toxicol Sci 35: 653-661, 2010.

18. O'Sullivan JB, Hanson R, Chan F And Bouchier-Hayes DJ: Tight glycaemic control is a key factor in wound healing enhancement strategies in an experimental diabetes mellitus model. Ir J Med Sci 180: 229-236, 2011.

19. Ribatti D: The discovery of the placental growth factor and its role in angiogenesis: a historical review. Angiogenesis: doi:10. 1007/s10456-008-9114-4. 